\title{
Awareness among the general population about lipid profile screening in individuals over 20 years old in Alriyadh, Saudi Arabia
}

\author{
Nasraddin Othman Bahakim ${ }^{1}$, Sameer Hamed Al-Ghamdi ${ }^{2}$, Hisham Fahad Alyahya ${ }^{3}$, \\ Khalid Bader Alburayk ${ }^{3}$, Yahya Ibrahim Mahzari ${ }^{3}$, Abdulrahman Mohammed Aldawsari ${ }^{3}$
}

\author{
'Basic Medical Sciences, College of Medicine, Prince Sattam bin Abdulaziz University, \\ Al Kharj, Saudi Arabia \\ ${ }^{2}$ Department of Family Medicine, College of Medicine, Prince Sattam bin Abdulaziz \\ University, Al Kharj, Saudi Arabia \\ ${ }^{3}$ undergraduate medical students, College of Medicine, Prince Sattam bin Abdulaziz \\ University, Al Kharj, Saudi Arabia
}

Submitted: 12 September 2018

Accepted: 9 October 2018

Arch Med Sci Atheroscler Dis 2019; 4: e126-e133

DOI: https://doi.org/10.5114/amsad.2019.85652

Copyright $\odot 2019$ Termedia \& Banach

\begin{abstract}
Introduction: Plasma cholesterol and triglycerides are clinically important because their abnormally high levels are major treatable risk factors for cardiovascular disease. This study aimed to evaluate the awareness, general knowledge, and attitudes about regular lipid profile screening among adult individuals in Al-Riyadh.

Material and methods: This is a cross-sectional study collected by convenience sampling method. Residents of Riyadh region older than 20 years were targeted through an electronic questionnaire distributed via Twitter and WhatsApp. The study was conducted between November 28, 2016 and December 31, 2016. Study results were analysed using the SPSS system. Results: This study included 1383 participants; 646 (46.7\%) were male and 737 (53.3\%) female. Of them, 905 (65.4\%) did not screen for their lipid profiles, while 478 (34.6\%) screened. A visit to a primary health care facility or hospital was the reason for screening of lipid profile in $195(14.1 \%)$ of the participants, whereas 64 (4.6\%) of them were ordered by doctors.

Conclusions: More educated participants were found to be more aware of the importance of screening lipid profile. Our results reflect poor awareness among the population regarding the importance of regular screening of lipid profiles. A visit to primary health care or hospital was the most frequent reason for screening of lipid profile. Screening lipid profiles was predominant among males and it was significantly related to the gender, age, and educational level. This shows the strong need in the community for health education about the importance of screening lipid profile at different levels of health care delivery.
\end{abstract}

Key words: lipid profile, cholesterol, lipoproteins, screening.

\section{Introduction}

There are three main classes of lipids in our blood, which include cholesterol, triglycerides (TG), and phospholipids. Functions of lipids include structural components of cellular membrane, energy storage as triglyceride, and cellular signalling. The initial steps in lipid cycle begin when it is

\author{
Corresponding author: \\ Nasraddin Othman \\ Bahakim \\ Basic Medical Sciences \\ College of Medicine \\ Prince Sattam bin \\ Abdulaziz Vniversity \\ 11942 Al Kharj, Saudi Arabia \\ E-mail: nasroden2010@ \\ gmail.com
}


absorbed from the gastrointestinal tract and mobilised throughout the body. Due to water insolubility nature of lipid molecules, lipids must be integrated within specific proteins called lipoproteins whenever this molecule is circulating within the blood [1]. Lipoproteins are classified on the basis of lipid-protein ratio, starting with chylomicrons, which carry dietary lipids from the intestines to various organs including liver, skeletal muscle, and adipose tissue. Very-low-density lipoproteins (VLDL) transport synthesised lipid from the liver to adipose tissue [2]. Low-density lipoproteins (LDL) are the main circulating lipoproteins, occasionally referred to as "bad" lipoprotein because it plays a major role in the formation of atheromatous plaques [3]. High-density lipoproteins (HDL) gather lipid molecules from the body's cells to transport it again to the liver. In contrast to LDL, HDL is referred to as "good" lipoprotein due to the correlation between higher concentration of HDL and improvement of health quality and atherosclerotic regression [4].

Plasma cholesterol and triglycerides are clinically important because their abnormally high levels are major treatable risk factors for cardiovascular disease; severe hypertriglyceridaemia also predisposes to acute pancreatitis. An increase in atherogenic lipoproteins, such as LDL, in the blood contributes to the development of atherosclerosis by subendothelial accumulation of these lipoproteins followed by their oxidation triggering an inflammatory response, which is mediated by macrophages to ultimately form foam cells, which in turn leads to endothelial dysfunction [5].

Coronary artery disease (CAD) is considered to be a very big threat to health in Saudi Arabia, being the third leading cause of mortality. Atherosclerosis is the underlying cause of CAD according to Kumosani et al. [6]. However, a study showed that the prevalence of CAD in Saudi Arabia was $5.5 \%$ [7]. Lipid profile screening studies in Saudi Arabia has started to show the magnitude of the problem. One study found that the prevalence of hypercholesterolaemia was $54.9 \%$ and $53.2 \%$ for males and females, respectively; hypertriglyceridaemia was $47.6 \%$ and $33.7 \%$ in males and females, respectively [8]. In the town of Al-kharj, a study showed that the prevalence among people above 13 years old was 43.3\% [9]. Another study in Saudi Arabia documented that among Saudi adults, the level of dyslipidaemia ranges from $20 \%$ to $44 \%$ with triglycerides abnormal at the top; $25 \%$ out of them expressed low levels of HDL [10].

A cross-sectional study conducted on samples from different countries in the middle east - including Saudi Arabia - reported low HDL in 55.5\%, and people with very high LDL comprised $58.4 \%$, high LDL were $36.2 \%$, and moderate LDL were $47.2 \%[11]$.
In USA Hispanic/Latino adults, a study showed that half of Hispanic/Latino adults with hypercholesterolaemia did not know that they were dyslipidaemic at the time of research screening [12].

This study aimed to evaluate awareness, general knowledge, and attitudes about positive and negative aspects of regular lipid profile screening among adult individuals over the age 20 years in Al-Riyadh city, Saudi Arabia.

\section{Material and methods}

This is a cross-sectional survey study collected by convenience sampling method. All residents of Riyadh region who are older than 20 years were targeted through a self-constructed electronic questionnaire assessing the general knowledge, attitude, and awareness of lipid profile screening distributed via Twitter and WhatsApp. The questionnaire contained closed end and multiple selection questions and was revised by experts. The study was conducted between November 28, 2016 and December 31, 2016.

The sample size was calculated by OpenEpi version three [13], employing the following considerations: the study population was about 5,500,000 inhabitants [14], keeping the confidence interval (CI) at $95 \%$. The sample size was calculated to be 1083 participants, which represents a confidence level of $99.9 \%$. For correction of any possible data loss the total sample would be 1383 .

At the beginning of the survey the participants were asked to provide some personal information: gender, age, marital status, educational level, occupation, place of residence, and pattern of lifestyle - including smoking and physical activity. Smoking was grouped into three categories "No" meant never smoked at all, "Yes" meant active smoker, and "used to smoke" meant used to smoke but not now.

Physical activity was grouped into six categories "No", "Sometimes" meant irregular exercise, "Once weekly", "Twice weekly", "Three times weekly", and "More than three times weekly". If the response was other than "No", the follow-up question should be answered "How strenuous is your physical activity?", which was grouped into two categories: "With sweating and increase of respiratory rate" and "Without sweating and increase of respiratory rate".

The participant was then asked if he/she had screened his/her lipid profile, and a further follow-up question if the answer was "Yes" was about the reason for screening, which was grouped into two categories: "Instruction from my doctor" or "Regular check-up ", and the participant was given a blank space to mention any other causes if any. Finally, a question about history of chronic diseases was included: "diabetes, 
hypertension, obesity, and other chronic diseases" as well as their opinion about regular lipid profile screening tests with the following choice of answers: "Strongly agree", "Agree", "Neither agree nor disagree", "Disagree", and "Strongly disagree".

The most common reasons for use of an electronic questionnaire over traditional paper style are: 1 - decreased expenses, 2 - rapid response, and 3 - increased response rate [15]

\section{Ethics}

Approval of the study was obtained from the institutional Ethics Committee.

\section{Statistical analysis}

The study results were analysed using the SPSS (V22) system, the following statistical tests were used: frequencies, multiple response sites, and bar charts. Relationships between questionnaire variables and gender, age, and personal or family history of chronic diseases were examined using the $\chi^{2}$ test.

\section{Results}

This study included a total of 1383 participants; 646 (46.7\%) were male and 737 (53.3\%) were female. Most of the participants (1027 (74.3\%)) were in the age group 20 to 35 years, and 176 (12.7\%) of them were over 35 years old.

Our results showed that 1057 (76.4\%) participants' academic qualification was bachelor's degree or higher, 310 (22.4\%) had high school or equivalent, and $16(1.2 \%)$ had intermediate school or lower. Highly educated participants, with bachelor's degree, were more commonly females. The educational level was found to be statistically significantly related to gender (Table I) and screening for lipid profile (Table II).

Furthermore, 502 (36.3\%) participants were unemployed, 432 (31.2\%) were employed, and $24(1.7 \%)$ were retired. Most of the jobless participants (314 (22.7\%)) were females, whereas most of the employees (305 (22.1\%)) were males, with a statistically significant relation between job status and gender (Table I).

Also, 1147 (82.9\%) respondents were nonsmokers, $66(4.8 \%)$ had stopped smoking, and only $170(12.3 \%)$ were smokers. Smoking was predominant among males (159 (11.5\%)), and it was significantly related to gender (Table I).

Exercise practicing was reported by 830 (60.1\%) of the participants, with 496 (35.9\%) of them practiced sometimes, and 198 (14.4\%) of them exercising three times or more per week. However, 553 (40\%) of the participants did not practice exercise at all. Exercise practicing was more com- mon among males, and it was significantly related to gender (Table I).

Regarding history of chronic diseases, 1086 (78.5\%) of the participants had no disease, 130 (9.4\%) had obesity, 22 (1.6\%) had diabetes mellitus, 17 (1.2\%) had hypertension, 98 (7.1\%) reported another disease, and 25 (1.8\%) of them had more than one disease. History of chronic diseases was significantly related to the gender and age (Tables I and III).

Moreover, 905 (65.4\%) of the respondents had not screen for their lipid profiles, while 478 (34.6\%) of them had screened. A visit to a primary health care (PHC) facility or hospital was the reason for screening of lipid profile in 195 (14.1\%) of the participants; whereas $64(4.6 \%)$ of them were instructed by doctors, and 170 (12.3\%) of them mentioned other causes. Screening of lipid profiles was predominant among males, and it was significantly related to the gender, age, and educational level (Tables I-III).

Majority of the respondents (1093 (79\%)), agreed with regular lipid profile screening testing, but $40(2.9 \%)$ of them disagreed, and 250 (18.1\%) of them expressed a neutral opinion. There was no statistically significant relation found between the respondents' opinion and their gender or their age (Tables I and III).

\section{Discussion}

Our results showed that $76.4 \%$ of the total 1383 participants' academic qualification was bachelor's degree or higher, $22.4 \%$ high school or equivalent, and $1.2 \%$ intermediate school or lower. Highly educated participants, with a bachelor's degree, were more commonly females. Educational level was found to be statistically significantly related to gender (Table I) and screening for lipid profile (Table II). This reflects the improvement of community education in comparison to a previous study - Ogbeide et al. found that $82.8 \%$ of their sample from Alkharj had less than high school education [9]. More educated participants were found to be more aware of the importance of lipid profile screening, in agreement with other studies $[16,17]$.

Furthermore, $36.3 \%$ of the participants were unemployed, $31.2 \%$ were employed, and $1.7 \%$ of them were retired. Most of the jobless participants $(22.7 \%)$ were females, whereas most of the employed respondents $(22.1 \%)$ were males, with a statistically significant relation between job status and gender (Table I). Most of the participants who did not undertake lipid profile screening were among the jobless group, in accordance with another study [17]; this may be attributed to decreased physical activity.

Moreover, $82.9 \%$ of the respondents were non-smokers, $4.8 \%$ had stopped smoking, and 
Table I. Relationship between questionnaire variables and gender

\begin{tabular}{|c|c|c|c|c|c|}
\hline \multirow[t]{2}{*}{ Variable } & \multirow[t]{2}{*}{ Answer } & \multicolumn{3}{|c|}{ Gender } & \multirow[t]{2}{*}{$P$-value } \\
\hline & & $\begin{array}{l}\text { Male } \\
N(\%)\end{array}$ & $\begin{array}{l}\text { Female } \\
N(\%)\end{array}$ & $\begin{array}{l}\text { Total } \\
N(\%)\end{array}$ & \\
\hline \multirow{5}{*}{$\begin{array}{l}\text { Educational } \\
\text { level }\end{array}$} & Intermediate school or lower & $5(0.4)$ & $11(0.8)$ & $16(1.2)$ & \multirow[t]{5}{*}{$0.024^{*}$} \\
\hline & High school or equivalent & $157(11.4)$ & $153(11.1)$ & $310(22.4)$ & \\
\hline & Bachelor's degree & $429(31.0)$ & $532(38.5)$ & $961(69.5)$ & \\
\hline & Higher & $55(4.0)$ & $41(3.0)$ & $96(6.9)$ & \\
\hline & Total & $646(46.7)$ & $737(53.3)$ & $1383(100)$ & \\
\hline \multirow[t]{7}{*}{ Job } & None & $188(13.6)$ & $314(22.7)$ & $502(36.3)$ & \multirow[t]{7}{*}{$<0.001^{\star}$} \\
\hline & Employee & $305(22.1)$ & $127(9.2)$ & $432(31.2)$ & \\
\hline & Other & $90(6.5)$ & $137(9.9)$ & $227(16.4)$ & \\
\hline & Free works & $44(3.2)$ & $73(5.3)$ & $117(8.5)$ & \\
\hline & Housekeeper & $1(0.1)$ & $80(5.8)$ & $81(5.9)$ & \\
\hline & Retired & $18(1.3)$ & $6(0.4)$ & $24(1.7)$ & \\
\hline & Total & $646(46.7)$ & $737(53.3)$ & $1383(100)$ & \\
\hline \multirow[t]{4}{*}{ Smoking } & Yes & $159(11.5)$ & $11(0.8)$ & $170(12.3)$ & \multirow[t]{5}{*}{$<0.001^{\star}$} \\
\hline & No & $423(30.6)$ & $724(52.3)$ & $1147(82.9)$ & \\
\hline & I was but then I quit & $64(4.6)$ & $2(0.1)$ & $66(4.8)$ & \\
\hline & Total & $646(46.7)$ & $737(53.3)$ & $1383(100)$ & \\
\hline \multirow[t]{7}{*}{ Exercise } & No & $255(18.4)$ & $298(21.5)$ & $553(40.0)$ & \\
\hline & Sometimes & $190(13.7)$ & $306(22.1)$ & $496(35.9)$ & \multirow[t]{6}{*}{$<0.001^{\star}$} \\
\hline & Once per week & $45(3.3)$ & $26(1.9)$ & $71(5.1)$ & \\
\hline & Twice per week & $40(2.9)$ & $25(1.8)$ & $65(4.7)$ & \\
\hline & Three times per week & $29(2.1)$ & $34(2.5)$ & $63(4.6)$ & \\
\hline & More than three times per week & $87(6.3)$ & $48(3.5)$ & $135(9.8)$ & \\
\hline & Total & $646(46.7)$ & $737(53.3)$ & $1383(100)$ & \\
\hline \multirow[t]{3}{*}{ Intensity } & With sweating and heavy breathing & $260(33.6)$ & $266(34.4)$ & $526(68.0)$ & \multirow[t]{3}{*}{0.091} \\
\hline & $\begin{array}{c}\text { Without sweating and heavy } \\
\text { breathing }\end{array}$ & $106(13.7)$ & $141(18.2)$ & $247(32.0)$ & \\
\hline & Total & $366(47.3)$ & $407(52.7)$ & $773(100)$ & \\
\hline \multirow{8}{*}{$\begin{array}{l}\text { Chronic } \\
\text { disease }\end{array}$} & None & $478(34.6)$ & $608(44.0)$ & $1086(78.5)$ & \multirow[t]{8}{*}{$<0.001^{*}$} \\
\hline & Diabetes & $16(1.2)$ & $6(0.4)$ & $22(1.6)$ & \\
\hline & Hypertension & $8(0.6)$ & $9(0.7)$ & $17(1.2)$ & \\
\hline & Heart problem & $3(0.2)$ & $2(0.1)$ & $5(0.4)$ & \\
\hline & Obesity & $78(5.6)$ & $52(3.8)$ & $130(9.4)$ & \\
\hline & Other disease & $44(3.2)$ & $54(3.9)$ & $98(7.1)$ & \\
\hline & More than one disease & $19(1.4)$ & $6(0.4)$ & $25(1.8)$ & \\
\hline & Total & $646(46.7)$ & $737(53.3)$ & $1383(100)$ & \\
\hline \multirow[t]{3}{*}{ Screening } & Yes & $258(18.7)$ & $220(15.9)$ & $478(34.6)$ & \multirow[t]{3}{*}{$<0.001^{*}$} \\
\hline & No & $388(28.1)$ & $517(37.4)$ & $905(65.4)$ & \\
\hline & Total & $646(46.7)$ & $737(53.3)$ & $1383(100)$ & \\
\hline \multirow{6}{*}{$\begin{array}{l}\text { Reason for } \\
\text { screening }\end{array}$} & Visit to $\mathrm{PHC}$ or hospital & $92(6.7)$ & $103(7.4)$ & $195(14.1)$ & \multirow[t]{6}{*}{$<0.001^{*}$} \\
\hline & Instructed by doctor & $35(2.5)$ & $29(2.1)$ & $64(4.6)$ & \\
\hline & Other cause & $105(7.6)$ & $65(4.7)$ & $170(12.3)$ & \\
\hline & None & $26(1.9)$ & $23(1.7)$ & $49(3.5)$ & \\
\hline & Did not perform & $388(28.1)$ & $517(37.4)$ & $905(65.4)$ & \\
\hline & Total & $646(46.7)$ & $737(53.3)$ & $1383(100)$ & \\
\hline
\end{tabular}


Nasraddin Othman Bahakim, Sameer Hamed Al-Ghamdi, Hisham Fahad Alyahya, Khalid Bader Alburayk, Yahya Ibrahim Mahzari, Abdulrahman Mohammed Aldawsari

Table I. Cont.

\begin{tabular}{|c|c|c|c|c|c|}
\hline \multirow[t]{2}{*}{ Variable } & \multirow[t]{2}{*}{ Answer } & \multicolumn{3}{|c|}{ Gender } & \multirow[t]{2}{*}{$P$-value } \\
\hline & & $\begin{array}{l}\text { Male } \\
N(\%)\end{array}$ & $\begin{array}{c}\text { Female } \\
N(\%)\end{array}$ & $\begin{array}{l}\text { Total } \\
N(\%)\end{array}$ & \\
\hline \multirow[t]{6}{*}{ Opinion } & Strongly agree & $239(17.3)$ & 259 (18.7) & $498(36.0)$ & 0.418 \\
\hline & Agree & $264(19.1)$ & 331 (23.9) & $595(43.0)$ & \\
\hline & Neutral & $120(8.7)$ & $130(9.4)$ & $250(18.1)$ & \\
\hline & Disagree & $19(1.4)$ & $15(1.1)$ & $34(2.5)$ & \\
\hline & Strongly disagree & $4(0.3)$ & $2(0.1)$ & $6(0.4)$ & \\
\hline & Total & $646(46.7)$ & 737 (53.3) & $1383(100)$ & \\
\hline
\end{tabular}

${ }^{*} P$-value determined by $\chi^{2}$-test means there is a statistically significant relationship at the level of significance (0.05 or less).

Table II. Relationship between educational level, lipid profile screening, and opinion

\begin{tabular}{|c|c|c|c|c|c|c|}
\hline \multirow[t]{2}{*}{ Parameter } & \multicolumn{4}{|c|}{ Educational level, $N$ (\%) } & \multirow[t]{2}{*}{ Total } & \multirow[t]{2}{*}{$P$-value } \\
\hline & $\begin{array}{l}\text { Intermediate } \\
\text { school or } \\
\text { lower }\end{array}$ & $\begin{array}{l}\text { High school } \\
\text { or equivalent }\end{array}$ & $\begin{array}{c}\text { Bachelor's } \\
\text { degree }\end{array}$ & Higher & & \\
\hline \multicolumn{6}{|l|}{ Screening: } & $<0.001^{*}$ \\
\hline Yes & $5(0.4)$ & $80(5.8)$ & $342(24.7)$ & $51(3.7)$ & $478(34.6)$ & \\
\hline No & $11(0.8)$ & $230(16.6)$ & $619(44.8)$ & $45(3.3)$ & $905(65.4)$ & \\
\hline Total & $16(1.2)$ & $310(22.4)$ & $961(69.5)$ & $96(6.9)$ & $1383(100)$ & \\
\hline \multicolumn{6}{|l|}{ Opinion: } & 0.380 \\
\hline Strongly agree & $5(0.4)$ & $109(7.9)$ & $343(24.8)$ & $41(3.0)$ & $498(36.0)$ & \\
\hline Agree & $8(0.6)$ & $131(9.5)$ & $421(30.4)$ & $35(2.5)$ & $595(43.0)$ & \\
\hline Neutral & $2(0.1)$ & $63(4.6)$ & $168(12.1)$ & $17(1.2)$ & $250(18.1)$ & \\
\hline Disagree & $1(0.1)$ & $6(0.4)$ & $26(1.9)$ & $1(0.1)$ & $34(2.5)$ & \\
\hline Strongly disagree & $0(0.0)$ & $1(0.1)$ & $3(0.2)$ & $2(0.1)$ & $6(0.4)$ & \\
\hline Total & $16(1.2)$ & $310(22.4)$ & $961(69.5)$ & $96(6.9)$ & $1383(100)$ & \\
\hline
\end{tabular}

${ }^{*} P$-value determined by $\chi^{2}$-test means there is a statistically significant relationship at the level of significance (0.05 or less).

only $12.3 \%$ were smokers. Smoking was predominant among males (11.5\%), and it was significantly related to the gender (Table I). Several studies reported the prevalence of smoking in Saudi Arabia ranging from $2.4 \%$ to $52.3 \%$ with a median of $17.5 \%$ [18]. This may be due to differences in study designs and populations. Tobacco is an important risk factor in ischaemic heart diseases and more atherogenic lipid profile [19]. Some studies showed raised levels of total cholesterol, triglycerides, LDL-C, and VLDL-C as well as low levels of HDL-cholesterol in smokers [20, 21].

Exercise practicing was reported by $60.1 \%$ of the participants; with $35.9 \%$ of them practicing sometimes and $14.4 \%$ of them exercising three times or more per week. However, $40 \%$ of the participants did not practice exercise at all. Exercise practicing was more common among males, and it was significantly related to gender (Table I). This reflects that most of the participants did not practice the regular advisable exercise, a finding that is approximately consistent with other studies [22, 23]; they reported, respectively, that $58.5 \%$ and $60 \%$ of the
Saudi adult population is physically inactive. Regular exercise plays an essential role in improving many body systems and biomarkers, including lipid profile, as well as reduction of the risk of non-communicable diseases [24]. Kannan et al. reported that LDL and diastolic blood pressure were significantly reduced with high intensity exercise [25].

Regarding history of chronic diseases, $78.5 \%$ of the participants had no chronic disease. However, $21.5 \%$ of the respondents reported a chronic disease: $9.4 \%$ had obesity, $1.6 \%$ had diabetes mellitus, $1.2 \%$ had hypertension, and $1.8 \%$ of them had more than one disease. History of chronic diseases was significantly related to the gender and age (Tables I and III). These findings are not consistent with other studies regarding the prevalence of these chronic diseases. It has been reported that the prevalence of these non-communicable chronic diseases among Saudi adult population was $28.7 \%$ for obesity [26], $24 \%$ for diabetes mellitus [27], and $15.2 \%$ for hypertension [28].

Majority of the respondents (65.4\%) did not screen for their lipid profiles; this reflects poor 
Table III. Relationship between questionnaire variables and age

\begin{tabular}{|c|c|c|c|c|c|c|}
\hline \multirow[t]{2}{*}{ Variable } & \multirow[t]{2}{*}{ Answer } & \multicolumn{4}{|c|}{ Age [years], $N(\%)$} & \multirow[t]{2}{*}{$P$-value } \\
\hline & & From 20 to 35 & Older than 35 & Other & Total & \\
\hline \multirow{5}{*}{$\begin{array}{l}\text { Educational } \\
\text { level }\end{array}$} & Intermediate sch. or lower & $4(0.3)$ & $6(0.4)$ & $6(0.4)$ & $16(1.2)$ & \multirow[t]{5}{*}{$<0.001^{*}$} \\
\hline & High school or equivalent & $159(11.5)$ & $30(2.2)$ & $121(8.7)$ & $310(22.4)$ & \\
\hline & Bachelor's degree & $790(57.1)$ & $123(8.9)$ & $48(3.5)$ & $961(69.5)$ & \\
\hline & Higher & $74(5.4)$ & $17(1.2)$ & $5(0.4)$ & $96(6.9)$ & \\
\hline & Total & $1027(74.3)$ & $176(12.7)$ & $180(13.0)$ & $1383(100)$ & \\
\hline \multirow[t]{4}{*}{ Smoking } & Yes & $114(8.2)$ & $43(3.1)$ & $13(0.9)$ & $170(12.3)$ & \multirow[t]{4}{*}{$<0.001^{*}$} \\
\hline & No & $869(62.8)$ & $120(8.7)$ & $158(11.4)$ & $1147(82.9)$ & \\
\hline & I was but then I quit & $44(3.2)$ & $13(0.9)$ & $9(0.7)$ & $66(4.8)$ & \\
\hline & Total & $1027(74.3)$ & $176(12.7)$ & $180(13.0)$ & $1383(100)$ & \\
\hline \multirow[t]{7}{*}{ Exercise } & No & $410(29.6)$ & $73(5.3)$ & $70(5.1)$ & $553(40.0)$ & \multirow[t]{7}{*}{0.847} \\
\hline & Sometimes & $368(26.6)$ & $60(4.3)$ & $68(4.9)$ & $496(35.9)$ & \\
\hline & Once per week & $49(3.5)$ & $9(0.7)$ & $13(0.9)$ & $71(5.1)$ & \\
\hline & Twice per week & $47(3.4)$ & $10(0.7)$ & $8(0.6)$ & $65(4.7)$ & \\
\hline & Three times per week & $45(3.3)$ & $9(0.7)$ & $9(0.7)$ & $63(4.6)$ & \\
\hline & $\begin{array}{l}\text { More than three times per } \\
\text { week }\end{array}$ & $108(7.8)$ & $15(1.1)$ & $12(0.9)$ & $135(9.8)$ & \\
\hline & Total & $1027(74.3)$ & $176(12.7)$ & $180(13.0)$ & $1383(100)$ & \\
\hline \multirow[t]{3}{*}{ Intensity } & $\begin{array}{c}\text { With sweating and heavy } \\
\text { breathing }\end{array}$ & $70(9.1)$ & $54(7.0)$ & $402(52.0)$ & $526(68.0)$ & \multirow[t]{3}{*}{0.138} \\
\hline & $\begin{array}{l}\text { Without sweating and } \\
\text { heavy breathing }\end{array}$ & $35(4.5)$ & $37(4.8)$ & $175(22.6)$ & $247(32.0)$ & \\
\hline & Total & $105(13.6)$ & $91(11.8)$ & $577(74.6)$ & $773(100)$ & \\
\hline \multirow[t]{8}{*}{ Disease } & Nothing & $837(60.5)$ & $115(8.3)$ & $134(9.7)$ & $1086(78.5)$ & \multirow[t]{8}{*}{$<0.001^{*}$} \\
\hline & Diabetes & $13(0.9)$ & $5(0.4)$ & $4(0.3)$ & $22(1.6)$ & \\
\hline & Hypertension & $8(0.6)$ & $7(0.5)$ & $2(0.1)$ & $17(1.2)$ & \\
\hline & Heart problem & $0(0.0)$ & $2(0.1)$ & $3(0.2)$ & $5(0.4)$ & \\
\hline & Obesity & $98(7.1)$ & $11(0.8)$ & $21(1.5)$ & $130(9.4)$ & \\
\hline & Other disease & $65(4.7)$ & $22(1.6)$ & $11(0.8)$ & $98(7.1)$ & \\
\hline & More than one disease & $6(0.4)$ & $14(1.0)$ & $5(0.4)$ & $25(1.8)$ & \\
\hline & Total & $1027(74.3)$ & $176(12.7)$ & $180(13.0)$ & $1383(100)$ & \\
\hline \multirow[t]{3}{*}{ Screening } & Yes & $353(25.5)$ & $83(6.0)$ & $42(3.0)$ & $478(34.6)$ & \multirow[t]{3}{*}{$<0.001^{*}$} \\
\hline & No & $674(48.7)$ & $93(6.7)$ & $138(10.0)$ & $905(65.4)$ & \\
\hline & Total & $1027(74.3)$ & $176(12.7)$ & $180(13.0)$ & $1383(100)$ & \\
\hline \multirow{6}{*}{$\begin{array}{l}\text { Reason for } \\
\text { screening }\end{array}$} & Visit to PHC or hospital & $129(9.3)$ & $53(3.8)$ & $13(0.9)$ & $195(14.1)$ & \multirow[t]{6}{*}{$<0.001^{*}$} \\
\hline & Instructed by doctor & $39(2.8)$ & $19(1.4)$ & $6(0.4)$ & $64(4.6)$ & \\
\hline & Other cause & $145(10.5)$ & $7(0.5)$ & $18(1.3)$ & $170(12.3)$ & \\
\hline & Unmentioned cause & $40(2.9)$ & $4(0.3)$ & $5(0.4)$ & $49(3.5)$ & \\
\hline & Did not perform & $674(48.7)$ & $93(6.7)$ & $138(10.0)$ & $905(65.4)$ & \\
\hline & Total & $1027(74.3)$ & $176(12.7)$ & $180(13.0)$ & $1383(100)$ & \\
\hline \multirow[t]{6}{*}{ Opinion } & Strongly agree & $377(27.3)$ & $64(4.6)$ & $57(4.1)$ & $498(36.0)$ & \multirow[t]{6}{*}{0.569} \\
\hline & Agree & $432(31.2)$ & $82(5.9)$ & $81(5.9)$ & $595(43.0)$ & \\
\hline & Neutral & $189(13.7)$ & $23(1.7)$ & $38(2.7)$ & $250(18.1)$ & \\
\hline & Disagree & $25(1.8)$ & $6(0.4)$ & $3(0.2)$ & $34(2.5)$ & \\
\hline & Strongly disagree & $4(0.3)$ & $1(0.1)$ & $1(0.1)$ & $6(0.4)$ & \\
\hline & Total & $1027(74.3)$ & $176(12.7)$ & $180(13.0)$ & $1383(100)$ & \\
\hline
\end{tabular}

${ }^{\star} P$-value determined by $\chi^{2}$-test means there is a statistically significant relationship at the level of significance ( 0.05 or less). 
awareness among the population regarding the importance of regular screening of lipid profiles. This finding is consistent with one study [29] but higher than that reported by another [16]. Hypercholesterolaemia and hypertension are prevalent medical problems affecting nearly half of the adult Saudi population [8].

A visit to a primary health care (PHC) facility or hospital was the reason for screening of lipid profile in $14.1 \%$ of the participants; whereas $4.6 \%$ of them were instructed by doctors, and $12.3 \%$ of them mentioned other causes. Screening of lipid profiles was predominant among males, and it was significantly related to the gender, age, and educational level (Tables I-III). This shows the strong need in the community for health education about the importance of screening lipid profiles at different levels of health care delivery, especially at PHCs. Several studies have reported the effectiveness of health counselling during PHC visits $[24,30]$.

The majority of the respondents (79\%) agreed with regular lipid profile screening tests, but $2.9 \%$ of them disagreed, and $18.1 \%$ of them expressed a neutral opinion. This shows that the majority of the community are ready to change to a better healthy lifestyle and practices according to the efforts of health care providers.

In conclusion, more educated participants were found to be more aware of the importance of screening lipid profile. Most participants who did not screen for lipid profiles were among the jobless group. The majority of the participants did not practice regular advisable exercise. Furthermore, $65.4 \%$ of the respondents did not screen for their lipid profiles; this reflects poor awareness among the population regarding the importance of regular screening of lipid profiles. A visit to a primary health care facility or hospital was the most frequent reason for screening of lipid profile. Screening of lipid profiles was predominant among males, and it was significantly related to gender, age, and educational level. This shows the strong need in the community for health education about the importance of screening for lipid profiles at different levels of health care delivery.

Recommendations: More studies about lipid profiles should be conducted, including different community groups. Implementation of fundamental policies including periodical screening of lipid profile at PHCs for all individuals $\geq 40$ years old or with a risk factor. Health promotion campaigns about lipid profile screening to improve health education in the general population.

\section{Conflict of interest}

The authors declare no conflict of interest.

\section{References}

1. Hall JE, Guyton AC. Guyton and Hall Teextbook of Medical Physiology. $13^{\text {th }}$ ed. Elsevier Saunders, Philadelphia 2016.

2. Nelson D, Nelson D, Lehninger A, Cox M. Lehninger Principles of Biochemistry. $5^{\text {th }}$ ed. W.H. Freeman, New York 2008.

3. American Heart Association (AHA). Good vs. bad cholesterol. Available at: http://www.heart.org/heartorg/ Conditions/Cholesterol/ Accessed: April 25, 2017.

4. Keene D, Price C, Shun-Shin MJ, Francis DP. Effect on cardiovascular risk of high density lipoprotein targeted drug treatments niacin, fibrates, and CETP inhibitors: meta-analysis of randomised controlled trials including 117411 patients. BMJ 2014; 349: g4379.

5. Kumar V, Abbas A, Fausto N, Robbins S, Cotran R. Robbins and Cotran Pathologic Basis of Disease. $9^{\text {th }}$ ed. Elsevier Saunders, Philadelphia 2015.

6. Kumosani TA, Alama MN, lyer A. Cardiovascular diseases in Saudi Arabia. Prime Res Med 2011; 1: 1-6.

7. Al-Nozha MM, Arafah MR, Al-Mazrou YY, et al. Coronary artery disease in Saudi Arabia. Saudi Med J 2004; 25: 1165-71.

8. Al-Nozha MM, Arafah MR, Al-Maatouq MA, et al. Hyperlipidemia in Saudi Arabia. Saudi Med J 2008; 29: 282-7.

9. Ogbeide DO, Karim A, Al-Khalifa IM, Siddique S. Population based study of serum lipid levels in Al-Kharj Health Center, Saudi Arabia. Saudi Med J 2004; 25: 1855-7.

10. Al-Kaabba AF, Al-Hamdan NA, El Tahir A, Abdalla AM, Saeed AA, Hamza MA. Prevalence and correlates of dyslipidemia among adults in Saudi Arabia: results from a national survey. Open J Endocrine Metab Dis 2012; 2: 89-97.

11. Al Sifri SN, Almahmeed W, Azar S, et al. Results of the Dyslipidemia International Study (DYSIS)-Middle East: clinical perspective on the prevalence and characteristics of lipid abnormalities in the setting of chronic statin treatment. PLoS One 2014; 9: e84350.

12. Rodriguez CJ, Cai J, Swett K, et al. High cholesterol awareness, treatment, and control among Hispanic/ Latinos: results from the Hispanic Community Health Study/Study of Latinos. J Am Heart Assoc 2015; 4: pii: e001867.

13. OpenEpi, Version 3. https://www.openepi.com/SampleSize/SSPropor.htm.

14. General Authority for Statistics Saudi Arabia. Census 2010: Distribution of population in administrative districts. www.stats.gov.sa.

15. Lazar J, Preece J. Designing and implementing Webbased surveys. J Computer Information Systems 1999; 39: 63-7.

16. Alahmari AS, Alrashed FM, Awad AR, et al. Knowledge, attitude and practice towards dyslipidemia among patients attending primary health care centers, Abha city, Saudi Arabia. Int J Adv Res 2016; 4: 1937-42.

17. Ni W, Liu X, Zhuo Z, et al. Serum lipids and associated factors of dyslipidemia in the adult population in Shenzhen. Lipids Health Disease 2015; 14-71. DOI 10.1186/ s12944-015-0073-77.

18. Bassiony MM. Smoking in Saudi Arabia. Saudi Med J 2009; 30: 876-81.

19. Gossett LK, Johnson HM, Piper ME, et al. Smoking intensity and lipoprotein abnormalities in active smokers. J Clin Lipidol 2009; 3: 372-8.

20. Jain RB, Ducatman A. Associations between smoking and lipid/lipoprotein concentrations among US adults aged $\geq 20$ years. J Circ Biomark 2018; 7: 1849454418779310. 
21. Gamit KS, Nanavati MG, Gohel PM, Gonsai RN. Effects of smoking on lipid profile. Int J Current Res Rev 2013; 5: 36-42.

22. Ministry of Health (MH). Survey of Health Information in Kingdom of Saudi Arabia 2013.

23. World Health Organization (WHO). Saudi Arabia Diabetes country profiles 2016. Geneva, Switzerland 2016.

24. Alahmed Z, Lobelo F. Physical activity promotion in Saudi Arabia: a critical role for clinicians and the health care system. J Epidemiol Global Health 2018; 7: S7-15.

25. Kannan U, Vasudevan K, Balasubramaniam K, Yerrabelli D, Shanmugavel K, John NA. Effect of exercise intensity on lipid profile in sedentary obese adults. J Clin Diagn Res 2014; 8: BC08-10.

26. Memish ZA, Bcheraoui CE, Tuffaha M, et al. Obesity and associated factors - Kingdom of Saudi Arabia, 2013. Centers for disease control and prevention. Preventing Chronic Dis 2014; 11: E174.

27. Guariguata L, Nolan T, Beagley J. International Diabetes Federation. IDF Diabetes Atlas. (th $^{\text {th }}$ ed. 2013.

28. Bcheraoui CE, Memish ZA, Tuffaha M, et al. Hypertension and its associated factors in the Kingdom of Saudi Arabia, 2013 - a national survey. Int J Hypertens 2014; 2014: 564679.

29. Ombon S, Carabelli G, Ghirardi E, Carugo S. Awareness, treatment, and control of major cardiovascular risk factors in a small-scale Italian community. Vasc Health Risk Manag 2013; 9: 177-85.

30. Fareed M, Salam N, Khoja AT, Mahmoud MA, Ahamed M. Life style related risk factors of type 2 diabetes mellitus and its increased prevalence in Saudi Arabia: a brief review. Int J Med Res Health Sci 2017; 6: 125-32. 